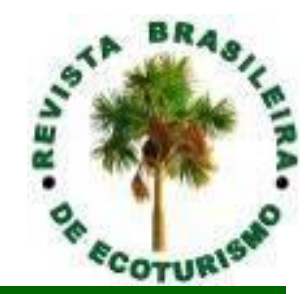

\title{
A importância dos parques urbanos para a manutenção da biodiversidade e benefícios socioambientais: uma análise realizada no Parque do Flamengo (Rio de Janeiro)
}

\section{The importance of urban parks for the maintenance of biodiversity and socio-environmental benefits: an analysis conducted at the Flamengo Park (Rio de Janeiro, Brazil)}

\author{
Phillipe Knippel do Carmo Graça, Flávio Pereira Telles
}

\begin{abstract}
RESUMO: O estudo buscou demonstrar os benefícios do Parque Brigadeiro Gomes - Aterro do Flamengo, RJ, para a fauna e sociedade, e identificar a percepção ambiental dos visitantes da área. Pela revisão teórica do tema sobre a conservação da biodiversidade em áreas urbanas foi feita uma pesquisa de campo através de questionário com 14 perguntas, aplicado a 200 visitantes do parque. $77,8 \%$ dos entrevistados são mulheres e a faixa etária que prevaleceu foi entre 26 a 39 anos. $43,4 \%$ dos entrevistados informaram que o maior benefício gerado pelo parque é a saúde, além disso, $79,6 \%$ mostraram insatisfação com a segurança local e $65 \%$ não aprovam a quantidade de áreas verdes disponíveis no Rio de Janeiro. Conclui-se que o Parque Aterro do Flamengo é notável para a evolução da cidade, pois realiza funções sócio-ambientais, oferece lazer, turismo, e ameniza a paisagem urbana gerando efeitos ambientais positivos para o entorno. O parque gera também benefícios no bem-estar dos frequentadores, na qualidade de vida e na saúde física e mental, conforme constatado. A massa vegetal existente no Parque do Flamengo é uma importante área de conservação em meio urbano para a sustentabilidade da cidade, oferece proventos à fauna e melhora a qualidade de vida dos habitantes.
\end{abstract}

PALAVRAS-CHAVE: Parques Urbanos; Desenvolvimento Sustentável; Cidades Verdes; Sustentabilidade; Parque do Flamengo.

ABSTRACT: The study sought to demonstrate the benefits of Brigadeiro Gomes Park - Aterro do Flamengo, RJ, for fauna and society, and to identify the environmental perception of visitors to the area. The theoretical review of the theme on biodiversity conservation in urban areas carried out a field survey through questionnaires with 14 questions, applied to 200 visitors to the park. $77.8 \%$ of respondents are women and the age group that prevailed was between 26 and 39 years old. $43.4 \%$ of respondents reported that the greatest benefit generated by the park is health, in addition, $79.6 \%$ showed dissatisfaction with local security and $65 \%$ did not approve the amount of green areas available in Rio de Janeiro. It is concluded that Aterro do Flamengo Park is notable for the evolution of the city, as it performs socio-environmental functions, offers leisure, tourism and softens the urban landscape, generating positive environmental effects for the surroundings. The park also generates benefits in the well-being of visitors, in the quality of life and in physical and mental health, as verified. The vegetal mass in Flamengo Park is an important area of conservation in an urban environment for the sustainability of the city, offers benefits to fauna and improves the quality of life of the inhabitants.

KEYWORDS: Urban Parks; Sustainable Development; Green Cities; Sustainability; Flamengo Park. 


\title{
Introdução
}

As metrópoles são os resultados de mais significância nas mudanças estruturais de um ambiente seguindo o comportamento dos sistemas econômicos, históricos e políticos, e devido à ação antrópica. Na cidade ocorre um grande número de transformações, além do fato de que quanto mais se expande, mais aumenta a chance de determinado local sofrer impactos.

O ambiente urbano é o resultado da interação dos fatores socioeconômicos, biológicos e ambientais, onde o meio criado pelo homem se sobrepõe ao meio físico, o que resulta em profundas mudanças sobre este e na qualidade de vida dos seres (LOMBARDO, 1990).

A urbanização das cidades provoca reflexos negativos na qualidade de vida dos moradores, o que faz com que as áreas verdes urbanas se tornem importantes para a população, quando esta busca por qualidade de vida. Desta forma, as áreas verdes urbanas visam o equilíbrio entre os processos de urbanização e a preservação do meio ambiente (LOBODA; ANGELIS, 2002).

Em relação às principais problemáticas socioambientais das cidades, Fernandes (2002, p.100) afirma que:

\begin{abstract}
A baixa qualidade ambiental de vida nas cidades tem sido agravada ainda mais pela diversidade de formas de poluição resultantes especialmente da produção industrial e do sistema dominante de transporte por automóveis. Dentre muitos outros problemas socioambientais existentes nas cidades, também devem ser mencionados os serviços públicos insuficientes; a distribuição desigual de equipamentos urbanos e comunitários; a falta de áreas verdes; os padrões inadequados de uso do solo; e a baixa qualidade técnica das construções.
\end{abstract}

As áreas verdes no meio urbano são importantes para determinar a qualidade de vida da população, já que atuam sobre o clima, a qualidade do ar, o nível de ruídos sonoros e na paisagem. Os ambientes verdes criados e a vegetação assumem um papel de destaque pelas funções desempenhadas, assim sendo, tratar da arborização, vias e canteiros no meio urbano e também parques, praças e áreas de refúgio de vida silvestre significa tratar das próprias estruturas da cidade (JAPYASSÚ; BRESCOVIT, 2006, p.3).

Os parques urbanos - um dos tipos de áreas verdes - são tidos como espaços apropriados para o lazer e para praticar atividades físicas, e dessa forma, órgãos internacionais têm dado atenção especial para a construção e revitalização dessas áreas que promovem e incentivam um estilo de vida ativo (LIBRETT et al., 2007). Algumas pesquisas citam determinantes ambientais tais qual a acessibilidade, disponibilidade, segurança, tráfego urbano, condições climáticas, atmosféricas, suporte social, crenças e atitudes como influenciadores da atividade física em parques urbanos (BEDIMO-RUNG et al., 2005; COHEN et al., 2004).

O ambiente que nos cerca desperta em nós determinadas sensações de forma que cada indivíduo faz sua interpretação desse espaço, criando uma imagem própria e exclusiva para representá-lo que se constitui na representação que um indivíduo, uma 
população ou uma parcela apresenta sobre o ambiente onde está inserida (PACHECO; SILVA, 2007).

Estudos de percepção subsidiam projetos, programas e atividades de educação ambiental formal e não formal, além de ajudarem a formular políticas públicas e conceder suporte para diversos tipos de estratégias a serem adotadas (REIGOTTA, 2002). Isto é, compreender como os indivíduos testemunham um parque urbano (valores ecológicos, recreacionistas, estéticos e até mesmo espirituais), e quais as expectativas eles possuem quanto aos mesmos, favorece a compreensão de sua gestão e conservação.

O trabalho apresentado objetivou mostrar dados e discussões sobre a área verde urbana existente na cidade do Rio de Janeiro conhecida como Parque do Flamengo e sua fundamental importância como forma de manutenção da biodiversidade dentro de um centro urbano brasileiro, visando assim a conservação da mesma além da importância desta para a vida da população. O estudo também investigou as percepções ambientais e sociais de um grupo de frequentadores do parque.

\section{Referencial Teórico}

\section{Parques urbanos: algumas considerações}

Os parques são resultados da transformação progressiva dos jardins, como explica Laurie (1983). A palavra jardim (garden) possui seu significado vindo da união de dois termos hebreus: gan, que significa proteger ou defender, como no caso de uma cerca; e, oden/eden, que significa deleite ou prazer, dando então a ideia de terra para prazer e deleite.

Para Macedo e Sakata (2010, p.14), parque urbano é todo espaço de uso público destinado à recreação de massa, qualquer que seja seu tipo, capaz de incorporar intenções de conservação e cuja estrutura morfológica é autossuficiente, isto é, não é diretamente influenciada em sua configuração por nenhuma estrutura constituída em seu entorno. Sendo assim, além de sua morfologia, tipos de uso e funções, fica obrigada a presença de vegetação arbórea, pois a massa vegetal e seus efeitos positivos no meio urbano é que diferenciam o parque dos outros tipos de áreas verdes, como as praças e jardins. Quando se trata de um parque ajardinado, os efeitos de porte arbóreo precisam ser dominantes.

Segundo Mendonça (2000), desde o final do século XIX que as teorias de urbanização tem se pautado na criação de jardins e parques urbanos como meio de melhorar a qualidade de vida na cidade, e parques, jardins e praças são de extrema importância no alicerce destas - desde as civilizações mais antigas que valorizavam estes ambientes - desempenhando uma função única na vida de sua população. Nessa perspectiva, parques e áreas verdes devem fazer parte da vida ambiental do meio urbano, especialmente em nossa atual sociedade.

Com a expansão das cidades e a destruição das florestas, aumentou o interesse por jardins e parques, um contrapondo à sociedade industrial, passando a ser parte da vida cotidiana urbana. Desta forma o parque urbano surge para equilibrar o processo de urbanização e a preservação do meio ambiente, possuindo aspectos culturais 
estéticos e sociais que devem ser encarados em diferentes funções, tempos e usos (LOBODA; ANGELIS, 2002).

Associados à ideia de preservação do meio ambiente surgem às primeiras noções de lazer e vida saudável. No século XIX, na Europa, médicos higienistas defendiam o conceito de criar nas cidades espaços ajardinados, com o intuito de promover um modo de vida mais saudável, frisando a necessidade dos parques para revigorar a atmosfera, os comparando a pulmões (SANTUCII, 2003).

No âmbito nacional, no século XIX o Brasil se estrutura como nação, e a vinda da família real portuguesa fez surgir a partir de 1808 a necessidade de se organizar. As cidades se estruturaram e sofreram modernizações para desempenhar novas funções administrativas. Em diversas cidades do Rio de Janeiro surgem áreas verdes, cuja implantação é aliada ao discurso higienista e à preocupação com a arborização e a paisagem, que passam a integrar a organização de algumas cidades brasileiras (TERRA, 2004).

Os três primeiros parques públicos que possuem as características morfológicas e funcionais atuais foram criados na mesma época, no Rio de Janeiro, sendo eles: o Jardim Botânico, próximo a Lagoa Rodrigo de Freitas, e o Passeio Público e o Campo de Santana, localizados no núcleo histórico e centro tradicional da cidade. No período do século $\mathrm{XX}$ os primeiros grandes parques projetados para o lazer público são implantados; as duas maiores cidades brasileiras recebem exemplares de grande importância, o Parque do Ibirapuera em São Paulo, e o Parque do Flamengo no Rio de Janeiro (MACEDO; SAKATA, 2003).

Vários benefícios podem ser obtidos pelo homem das cidades devido às áreas verdes, conforme alguns autores como Henke-Oliveira (1996), Vieira (2004), Toledo e Santos (2008), por exemplo, o controle de ruído e poluição do ar, aumento do conforto ambiental, estabilização de superfícies por meio da fixação do solo pelas raízes das plantas, abrigo à fauna, equilíbrio do índice de umidade no ar, proteção dos mananciais e nascentes, composição e organização de espaços no desenvolvimento das atividades humanas, valorização ornamental e visual do ambiente, recreação e diversificação da paisagem construída.

Locais arborizados públicos tais quais os parques urbanos e áreas ajardinadas, além de trazerem funções ambientais como reduzirem extremos climáticos (frio/calor), contribuem de outras formas ecológicas sendo mais atrativas para a fauna, por exemplo, já que acabam por oferecer alimento e abrigo. No que diz respeito ao caráter social, praças, jardins e parques públicos urbanos acabam provendo também resultados no âmbito estético, educativo e psicológico para seus habitantes. Tornamse locais para a prática de esportes e lazer, assim como palcos de eventos ligados à cultura, ações de cunho social e atividades comerciais.

A presença de composição florística também possui efeitos diretos sobre a saúde mental e física da população (MATIAS; CAPORUSSO, 2008). Áreas verdes atuam de forma positiva no psicológico humano devido a todos os benefícios acarretados ao bem-estar do homem, quando em contato com a vida selvagem. A melhoria da qualidade de vida nos centros urbanos está ligada diretamente a fatores de infraestrutura, desenvolvimento socioeconômico e àqueles ligados à questão ambiental, constituindo elementos imprescindíveis para o bem estar da população. Com a intenção de melhorar a qualidade de vida, seja através da recreação, preservação ambiental, áreas de preservação dos recursos hídricos, e à própria sociabilidade, essas áreas se constituem como atenuantes da paisagem urbana (LOBODA; ANGELIS, 
2002). O simples fato de uma pessoa observar uma árvore florida ao sair de casa, ouvir canto dos pássaros, respirar ar puro e sentir prazer por estar naquele lugar, amenizando o estresse da vida urbana agitada, já é gratificante para qualquer ação tomada nesse sentido (BRUN; BRUN, 2006).

É evidente a importância dos parques urbanos para as cidades, e mesmo sendo inúmeros os benefícios descritos, facilmente se percebe que por diversas vezes os espaços dos mesmos não são geridos de forma devida, desta forma, problemas do cunho ambiental acabam por não serem resolvidos ou mitigados. Problemas envolvendo verba e gestão acabam por não permitirem ou dificultarem a realização de pesquisas sobre a biodiversidade e recuperação de áreas que buscam obter resultados sobre a qualidade ambiental de parques urbanos.

\section{Material e Métodos}

\section{Área de estudo}

O presente trabalho foi realizado no oficialmente nomeado Parque Brigadeiro Eduardo Gomes, mais conhecido como Parque do Flamengo ou Aterro do Flamengo, situado na zona sul da cidade do Rio de Janeiro, na região administrativa IV. O bairro possui fronteira com os bairros: Laranjeiras, Botafogo, Glória e Catete (Figura 1).

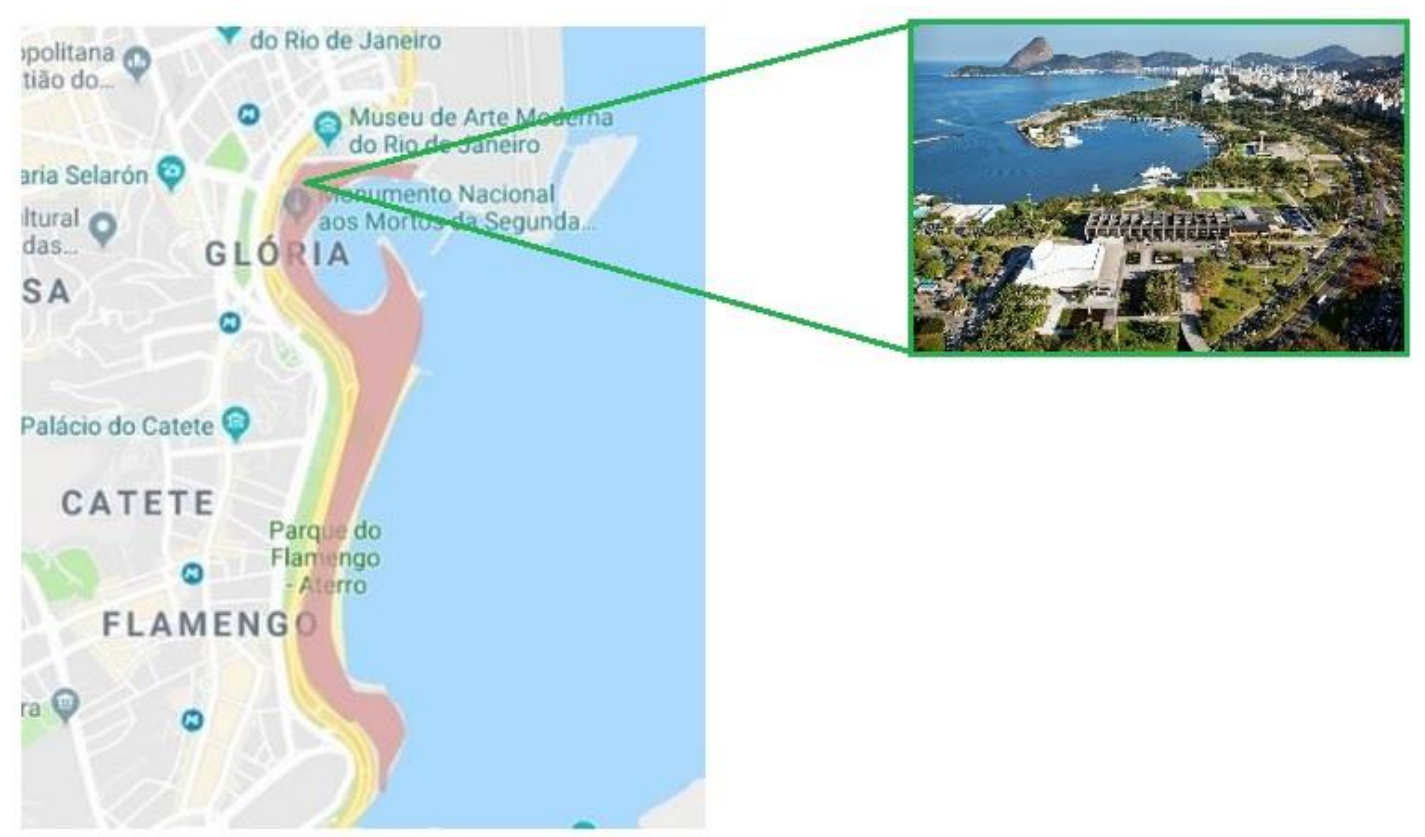

Figura 1: Bairros que o Parque do Flamengo abrange. Figure 1: Neighborhoods that include Flamengo Park.

Fonte: Google Maps (2018).

Source: Google Maps (2018).

Conforme o Instituto Pereira Passos, o bairro do Flamengo abrange uma área total de 164,63 hectares, desses, 123,94 hectares são de área edificada; e a população do bairro era de 50.043 habitantes em 2010. O parque é a mais extensa área de lazer da cidade e se situa junto à orla da Baía de Guanabara, sendo a maior parte dela 
contígua à praia do Flamengo. Abrange uma faixa de terra que se estende desde o Aeroporto Santos Dumont até o Morro da Viúva, em Botafogo.

O tratamento paisagístico moldou o terreno com um suave relevo gramado e implantou bosques homogêneos em toda a sua extensão. A intenção do projeto foi a de prover diversidade tanto no porte das árvores utilizadas quanto nos tons de verde da vegetação, composta em sua maior parte de espécies arbóreas nativas do Brasil, com florações sucessivas durante o ano inteiro.

A área do parque oferece uma variedade de equipamentos esportivos e culturais, somados à possibilidade de se apreciar a paisagem do entorno, como o Pão de Açúcar, - Morro da Urca, Corcovado, Bahia de Guanabara, a cidade de Niterói e o variado conjunto arquitetônico da Praia do Flamengo, com exemplares dos estilos eclético, art déco e modernista.

\section{A biodiversidade do Parque do Flamengo}

O Parque do Flamengo possui uma fauna considerável, sendo sua maior parte formada pelas aves, que são atraídas devido à grande diversidade de vegetação e árvores frutíferas da área. A maior parte das espécies residentes é de pequeno porte, e a biodiversidade do parque é enriquecida periodicamente por algumas espécies vindas de outras áreas verdes. Ao se aventurar pelo interior do parque, entre as pistas da ciclovia e o mar, uma variedade de pássaros pode ser observada. Nicolau Thomson (2015) registrou 86 espécies no parque, como por exemplo, Pyrrhura cruentata Wied (tiriba), Tangara cayana Linnaeus (saíra-amarela) e outras.

De acordo com o Guia das Unidades de Conservação Ambiental do Rio de Janeiro (1998), a composição florística é predominantemente arbórea, com alguns exemplares de porte arbustivo plantados no ano de 1998 pela Fundação Parques e Jardins. As espécies usadas no projeto inicial do parque foram em sua maioria nativas de outras regiões do Brasil, porém, existem ainda algumas espécies originárias de outros países.

As espécies arbóreas frequentemente encontradas são a Ficus microcarpa Linnaeus - Moraceae (figueira), a Roystonea oleraceae O.F. Cook - Arecaceae (palmeira-imperial), a Terminalia catappa Linnaeus - Combretaceae (amendoeira), o Delonix regia Bojer ex Hook - Fabaceae (flamboyant), a Bombax malabaricum D.C.Malvaceae (paineira-vermelha), Chrysalidocarpus lutescens - Aracaceae (areca) e a Tamarindus indica L. - Fabaceae (tamarineira).

Entre as espécies exóticas, foram muito utilizadas a Corypha umbraculifera $L$. Aracaceae (palmeira-asiática), o Sterculia foetida Linnaeus - Malvaceae (xixá) e a Livistona chinensis Jacquin R. Brown ex Martius - Aracaceae (palmeira-leque). As espécies nativas mais frequentes são o Libidibia ferrea Benth Ducke - Fabaceae (pauferro), o Couroupita guianensis Aublet - Lecythidaceae (abricó-de-macaco), a Chorisia speciosa St.Hil - Malvaceae (paineira), o Syagrus romanzoffiana Glassman Aracaceae (coqueiro-baba-de-boi), a Eugenia uniflora L. - Myrtaceae (pitangueira) e o Handroanthus impetiginosus (Mart. ex DC.) Mattos - Bignoniaceae (ipê-roxo) (Guia das Unidades de Conservação Ambiental do Rio de Janeiro, 1998).

O fato do Parque do Flamengo apresentar espécies vegetais que foram justamente escolhidas no projeto de forma que durante todo o ano houvesse períodos de floração, provavelmente indica um favorecimento na disponibilidade de fontes 
alimentares ao longo de todo o período anual para a família das abelhas, garantindo atividade de voo até no inverno.

\section{Amostragem de dados}

O trabalho apresentado utilizou dois meios para atingir o seu objetivo: a pesquisa bibliográfica (dados primários) e a aplicação de questionário aos frequentadores do parque (dados secundários). O primeiro método corresponde a uma técnica de pesquisa indireta, e o segundo método como uma técnica direta de captação de informações.

Segundo Malheiros (2000), a pesquisa bibliográfica eleva o conhecimento disponível na área, identificando as teorias produzidas, analisando-as e avaliando sua contribuição para a compreensão ou explicação do problema objeto de investigação. Tal procedimento é essencial para todos os tipos estudo de investigação, uma vez que não se pode conduzir o estudo de algo sem a identificação do que já foi produzido acerca do assunto, desta forma evitando dar crédito de inédito a algum conhecimento já existente, repetir estudos já desenvolvidos, assim como elaborar pesquisas destituídas de fundamentação teórica.

A aplicação dos questionários e a coleta de informações foram por meio de entrevistas aos frequentadores do parque. A pesquisa de campo foi realizada em quatro dias de semana e dois finais de semana, nos meses de Abril e Maio, no ano de 2016, no Parque Aterro do Flamengo, na cidade do Rio de Janeiro, Brasil. Em cada oportunidade foram entrevistadas vinte e cinco (25) pessoas que frequentam o local, totalizando uma amostra de duzentos (200) entrevistados.

Essa mediação teve o objetivo de identificar os benefícios sociais e ambientais do Aterro do Flamengo percebidos pelos frequentadores, bem como identificar as ações necessárias para a prática da sustentabilidade e da administração do mesmo.

Buscou-se também identificar a percepção ambiental dos frequentadores em relação ao parque. Sabe-se que o local é conhecido por proporcionar a prática do lazer sem deixar de lado o meio ambiente e a importância de preservar uma área verde tão exuberante dentro da cidade. Buscou-se identificar ainda se os entrevistados percebem a necessidade de mais segurança no local ou dos frequentadores mudarem o comportamento em prol da conservação do ambiente. Os formatos de respostas eram tanto fechados (dicotômicas, múltiplas opções), escala de ranking ou abertos.

O questionário abordou uma ampla gama de questões, desde os motivos pela natureza, imagens da natureza, a percepção das funções e atitudes ambientais. $O$ principal interesse em conduzir a análise de dados foi desdobrar o pensamento das pessoas e suas percepções em uma forma qualitativa, ao invés de estabelecer relações quantitativas ou identificar variáveis dependentes do grupo.

Estatística descritiva básica foi aplicada, e foi dada atenção também à análise qualitativa e interpretação da riqueza de dados obtidos.

Os resultados fornecem informações interessantes para planejadores de cidades e desenvolvedores urbanos, sobre o papel e a importância de espaços verdes para o bem-estar diário e qualidade de vida dos cidadãos. 


\section{Resultados e Discussão}

\section{A percepção ambiental dos visitantes do Parque do Flamengo}

A pesquisa foi feita com público maior de idade, com entrevistados de faixa etária à partir de 18 anos, como informado na Tabela 1, e em relação à média da idade, a opção mais assinalada foi a de "26 a 39 anos".

Tabela 1: Faixa etária dos entrevistados.

Table 1: Age range of respondents.

\begin{tabular}{cc}
\hline Faixa etária dos entrevistados & Quantidade \\
\hline 18 a 25 & 30 \\
26 a 39 & 70 \\
40 a 50 & 42 \\
51 a 69 & 50 \\
70 ou mais & 8 \\
Total & 200 \\
\hline
\end{tabular}

Fonte: Resultados da pesquisa (2016).

Source: Search results (2016).

O tamanho da amostra é $\mathrm{N}=200$, e conforme indica a Figura 2, predominantemente constituído por mulheres (77,8\%), e o nível superior é o nível de escolaridade da maioria (89\%) dos frequentadores entrevistados, conforme a Figura 3.

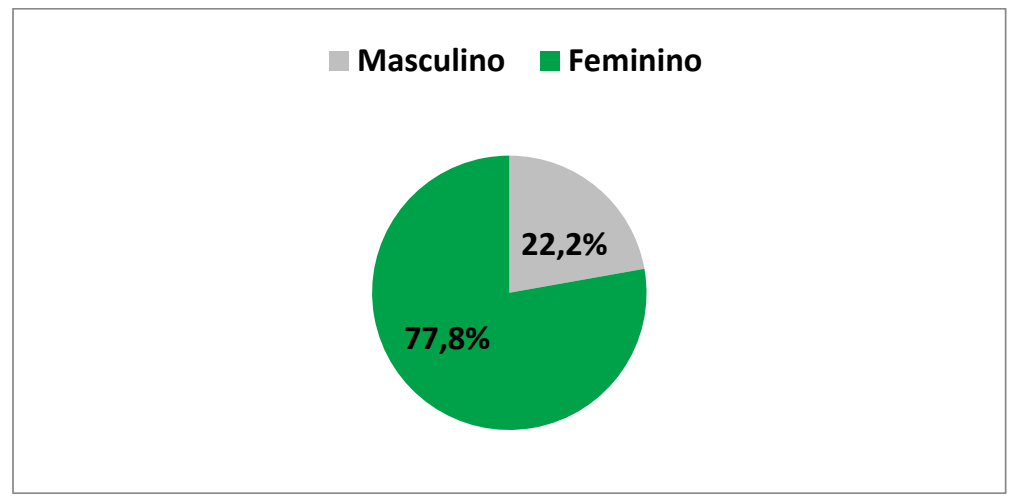

Figura 2: Gênero dos frequentadores do Parque Aterro do Flamengo, Rio de Janeiro, Brasil.

Figure 2: Gender of visitors to the Aterro do Flamengo Park, Rio de Janeiro, Brazil.

Fonte: Resultado da pesquisa (2016).

Source: Search results (2016).

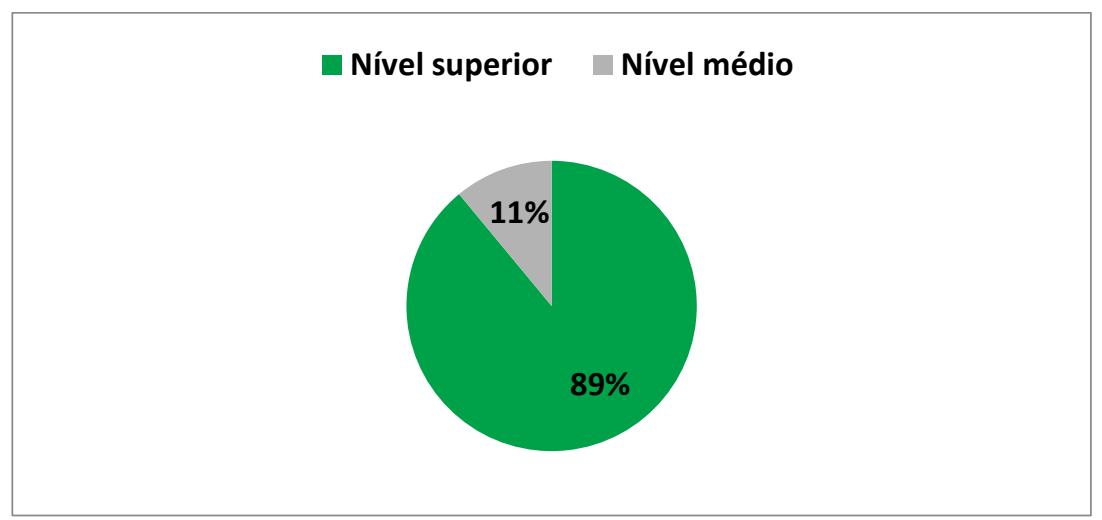

Figura 3: Nível de escolaridade dos frequentadores do Parque Aterro do Flamengo. Rio de Janeiro.

Figure 3: Schooling level of visitors to Parque Aterro do Flamengo. Rio de Janeiro, Brazil.

Fonte: Resultados da pesquisa (2016).

Source: Search results (2016). 
As questões buscavam informações a respeito da "relação dos visitantes com o parque" (Categoria I), "percepção ambiental dos frequentadores para com os benefícios gerados pelo parque" (Categoria II), "dimensão emocional e importância diária" (Categoria III), e sobre a "satisfação pública com a quantidade de áreas verdes" (Categoria IV), ambos mostrados na Figura 4.

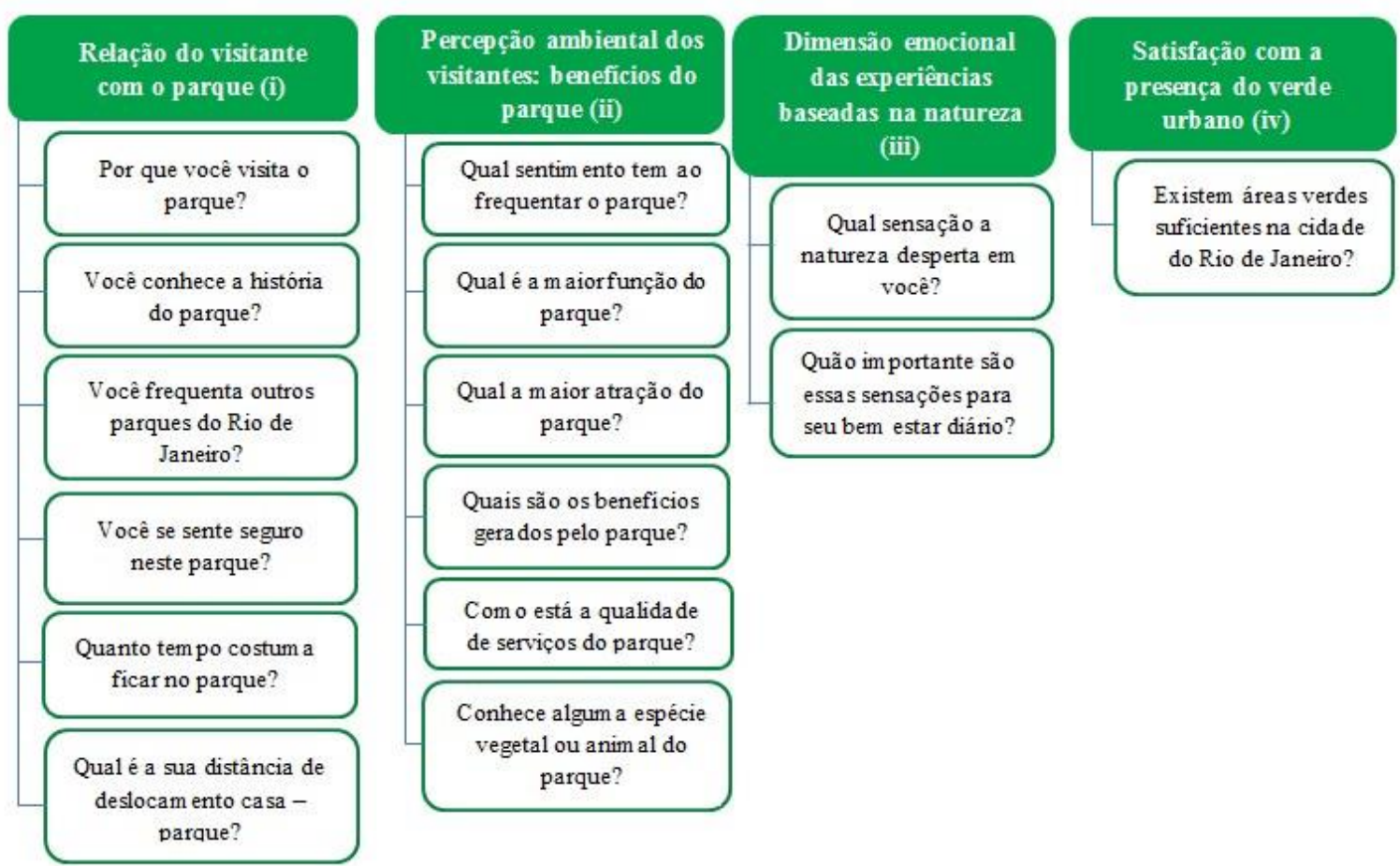

Figura 4: Categorias de questionamentos realizados aos frequentadores.

Figure 4: Categories of questions asked to visitors.

Fonte: Resultados da pesquisa (2016)

Source: Search results (2016).

Quanto à Categoria I (relação dos visitantes com o parque), foram obtidas as informações apresentadas nas figuras $5 \mathrm{a}$ a $5 \mathrm{f}$.

Os motivos pelos quais as pessoas visitam áreas naturais e as diversas atividades que elas executam refletem as demandas pessoais por locais em áreas naturais, e as necessidades que elas esperam preencher.

Essa informação pode ajudar tomadores de decisões para formular estratégias em sintonia com as necessidades públicas e expectativas.

$\mathrm{Na}$ coleta de dados sobre o motivo das pessoas visitarem o parque do Flamengo, os entrevistados foram perguntados: "Por que você visita o parque?". Dentre as opções de respostas apresentadas, "Praticar esportes" é o motivo mais frequentemente mencionado pelos visitantes apontando por $42,6 \%$ das respostas (Figura $5 a$ ). 


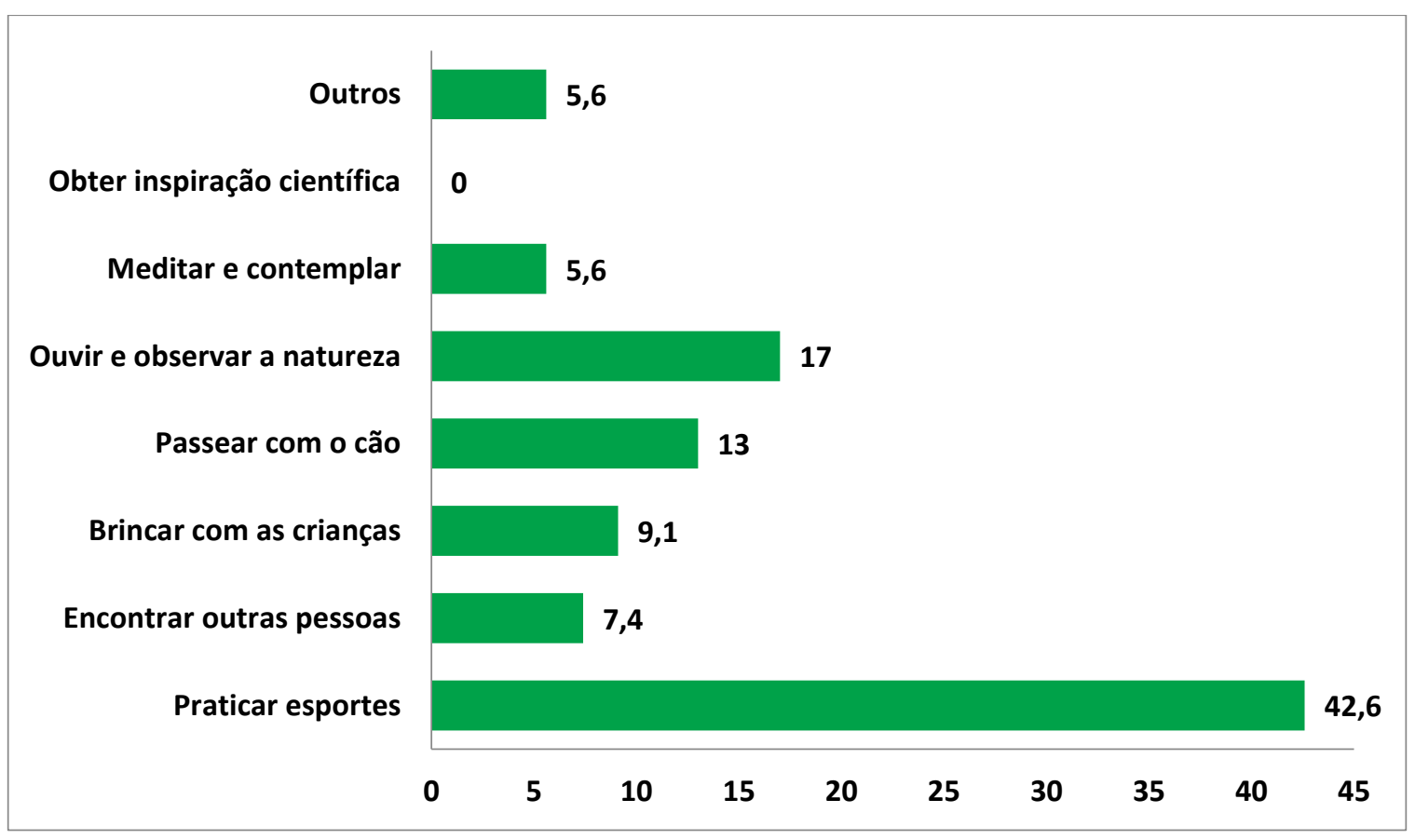

Figura 5a: Os motivos das visitas ao Parque Aterro do Flamengo.

Figure 5a: The reasons for the visits to the Aterro do Flamengo Park.

Fonte: Resultados da pesquisa (2016).

Source: Search results (2016).

Esse resultado demonstra que os parques urbanos são áreas verdes que podem ser usados para trazer qualidade de vida para a população, pois proporcionam contato com a natureza, e suas estruturas e qualidade ambiental quando adequadas e atrativas são determinantes para a realização de atividade física e o lazer. Estas atividades trazem diferentes benefícios psicológicos, sociais e físicos para a saúde dos indivíduos, como, por exemplo, a redução do sedentarismo e a diminuição do estresse do cotidiano urbano, se revelando como significativas estratégias para uma política efetiva da saúde pública.

"Ouvir e observar a natureza" constitui outro importante motivo para se visitar o parque (16,7\%). Esse motivo reflete a necessidade de sentir a natureza ao redor, de observar seus elementos e experimentá-los através dos sentidos (olfato, audição, visão e tato). Muitos visitantes mencionaram também a necessidade de ver outras coisas além de carros, concreto e construções. Nessa concepção, a natureza urbana oferece a possibilidade de escapar não somente das preocupações e da rotina diária, mas também no sentido físico da cidade. Os resultados também indicaram que quase 13\% dos entrevistados visitam o parque para passear com o cão, demonstrando que os parques urbanos também ajudam a fortalecer os laços dessa antiga amizade entre o homem e cães. "Nós já domesticamos os cães durante um longo período de tempo. Os reproduzimos seletivamente para atuar como nossos companheiros. Assim, os cães que responderam sensivelmente às nossas pistas emocionais, podem ter sido os indivíduos mais propensos a serem mantidos como animais de estimação e reproduzidos", assegura Deborah Custance (2012), co-autora do livro "Animal Cognition". Afirma ainda que "Eu acho que existe uma boa razão pra suspeitar que os cães sejam mais sensitivos às emoções humanas que outras espécies". Pesquisas mostram que acariciar um cão pode diminuir a ansiedade, regular a respiração e 
diminuir a pressão sanguínea, e um estudo japonês descobriu que apenas ao olhar para um cão pode-se aumentar os níveis de oxitocina, uma substância química liberada pela glândula pituitária que está associada com vínculo humano e carinho.

Visitar o parque para "brincar com as crianças" é a opção de quase $10 \%$ dos frequentadores. Neste sentido, a natureza preenche importantes funções sociais, fortalecendo laços familiares e providenciando locais seguros para as crianças brincarem, algo cada vez mais escasso nas cidades grandes. Os benefícios resultantes dessas funções advêm ambos, pais e filhos. Tem sido sugerido que a percepção de desafio e aventuras experimentadas na natureza pelas crianças, contribui positivamente para o seu desenvolvimento (CORNELL; HADLEY, 2001).

As razões "Meditar e contemplar" e "Encontrar outras pessoas" seguem em ordem decrescente de frequência. Estes motivos refletem a necessidade de experimentar a solidão e se bastar, bem como fazer novos contatos pessoais e se envolver em relações sociais.

Em relação à história do parque, a maior parte (Figura $5 b$ ) dos entrevistados conhece a história do Parque do Flamengo, e alguns que declaram não conhecer a história demonstraram curiosidade ao perguntar sobre a criação do mesmo.

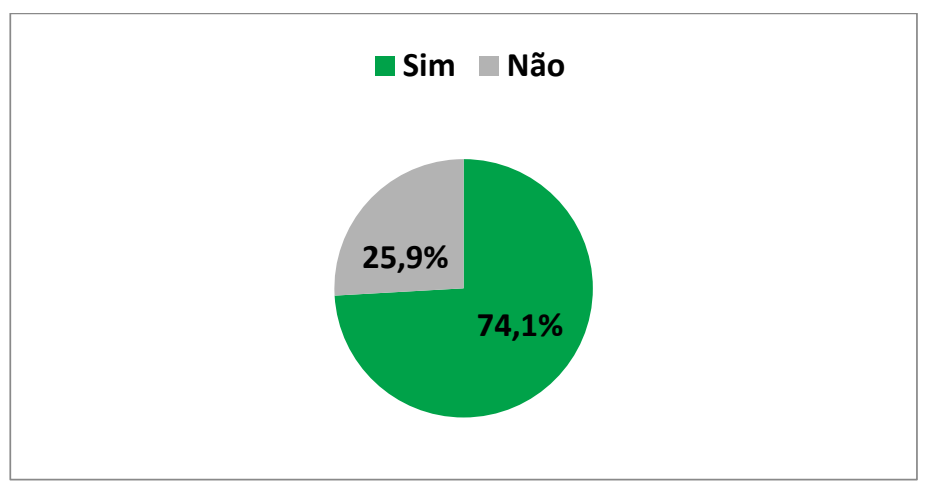

Figura 5b: Conhecimento sobre a história do Parque do Flamengo.

Figure 5b: Knowledge about the history of Flamengo Park.

Fonte: Resultados da pesquisa (2016).

Source: Search results (2016).

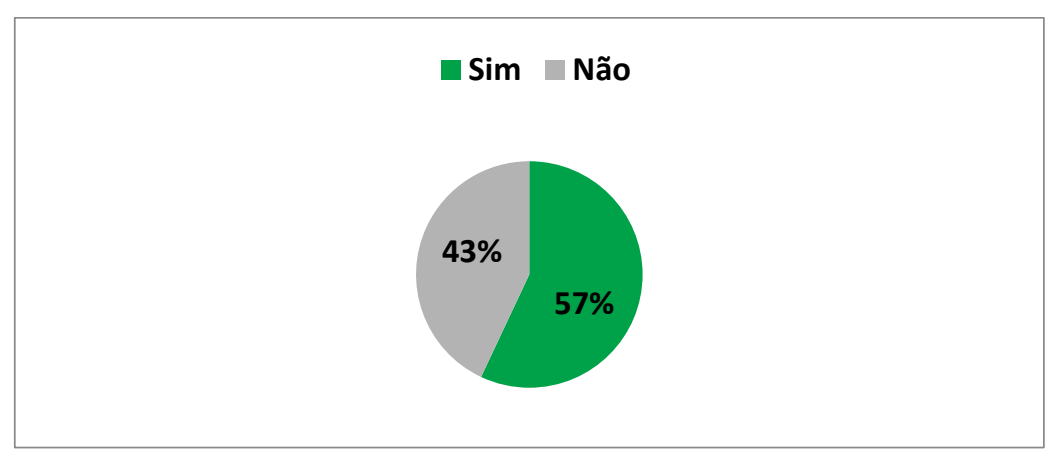

Figura 5c: Possui o hábito de visitar outros parques.

Figure 5c: Has a habit of visiting other parks.

Fonte: Resultados da pesquisa (2016).

Source: Search results (2016). 
Quanto à segurança do parque, nos horários em que as entrevistas foram aplicadas, pode-se verificar que a maioria dos frequentadores (Figura $5 d$ ) não se sentia segura. As pessoas que frequentam o parque, tanto na parte da manhã quanto nos finais de tarde não estão totalmente satisfeitas com relação à segurança no local, e reclamaram da ausência do Estado mencionando sobre cobrar melhorias sobre o parque.

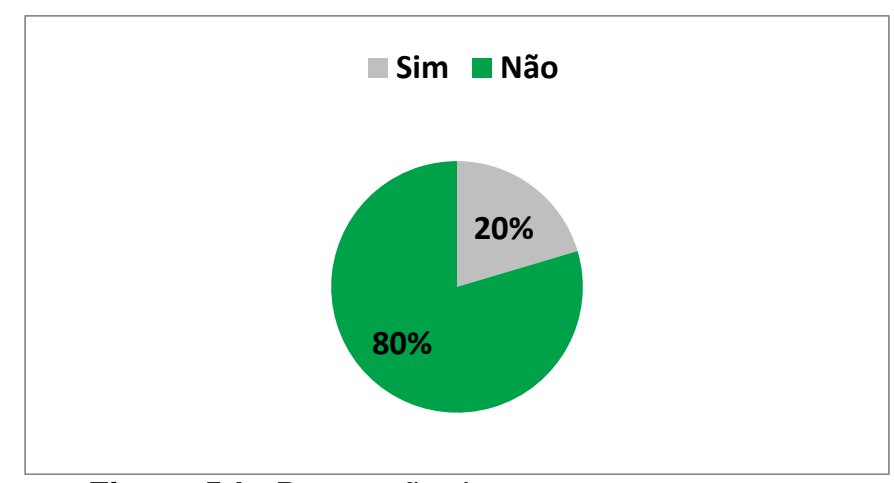

Figura 5d - Percepção de segurança no parque Figure 5d: Perception of safety in the park Fonte: Resultados da pesquisa (2016).

Source: Search results (2016).

O tempo que os frequentadores ficam no parque pode indicar uma alta rotatividade no fluxo do público visitante, uma vez que a maioria dos entrevistados (Figura 5e) respondeu ter o costume de ficar até somente 1 hora no parque.

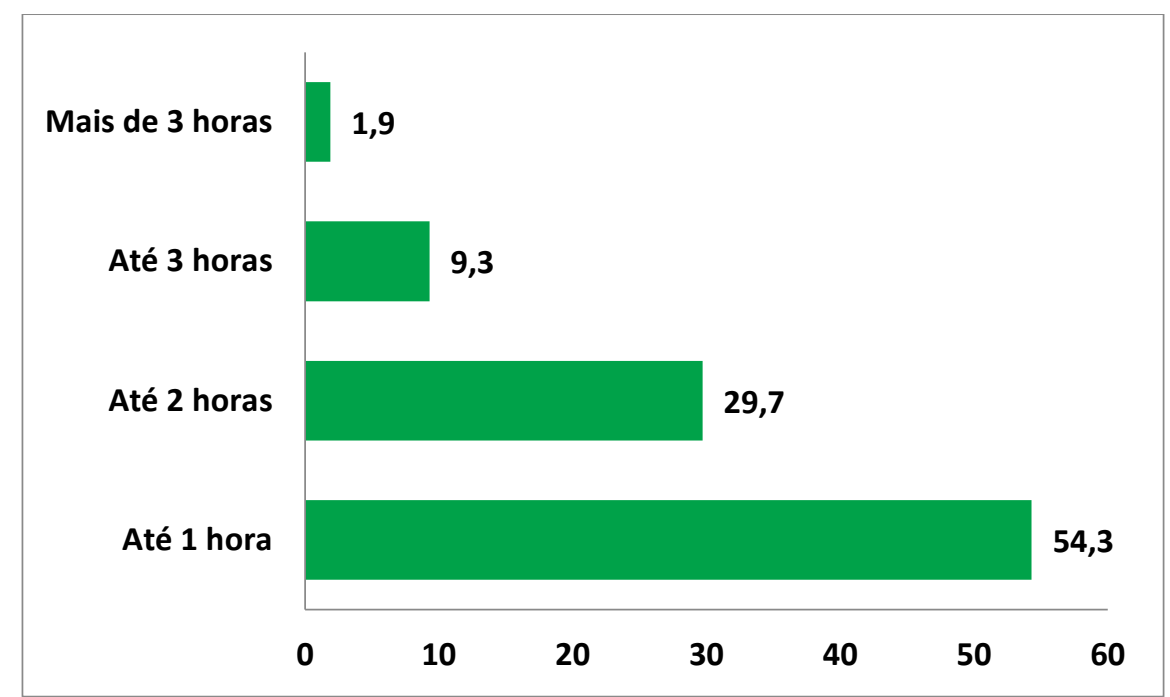

Figura 5e: Quanto tempo costuma ficar no parque.

Figure 5e: How long do you usually stay in the park.

Fonte: Resultados da pesquisa (2016).

Source: Search results (2016).

A infraestrutura de lazer parece ser o que motiva a presença dos frequentadores, pelo fato da maioria $(59,3 \%)$ (Figura $5 f)$ residir no entorno (até $1 \mathrm{~km}$ ), além de frequentarem outros parques $(57,4 \%)$ (Figura $5 \mathrm{c}$ ). 


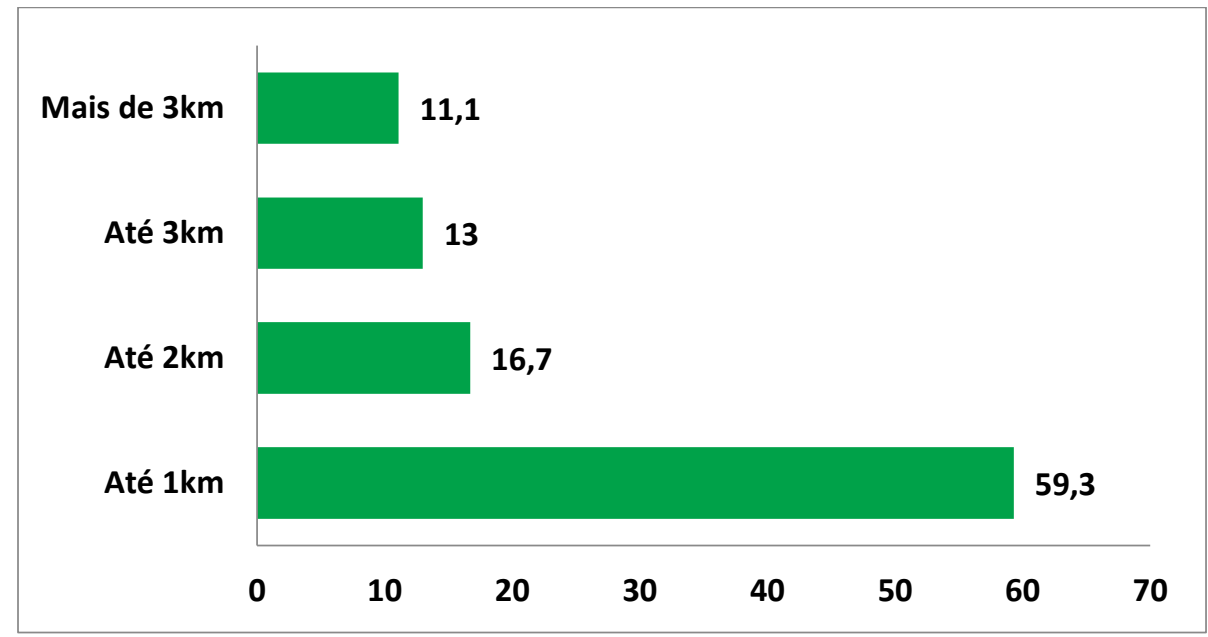

Figura 5f: Distância percorrida pelos visitantes de casa ate o parque. Figura 5f: Distance traveled by visitors from home to the park.

Fonte: Resultados da pesquisa (2016).

Source: Search results (2016).

A percepção ambiental dos frequentadores quanto aos benefícios gerados pelo parque, questionados na Categoria II, por possuir alternativas que apresentavam benefícios sociais e ambientais e um dos objetivos do trabalho era notar se os frequentadores eram capazes de identificar benefícios à conservação do meio ambiente e à sociedade, foi permitido aos entrevistados assinalarem mais de uma alternativa. As figuras $6 \mathrm{a}$ a $6 \mathrm{f}$ demonstram os resultados da Categoria II.

A maioria dos frequentadores (52,8\%) (figura $6 \mathrm{a}$ ) afirmou ter sentimento de "satisfação" ao frequentar o Parque do Flamengo, seguido pelo sentimento de "tranquilidade", mesmo com o entendimento de que a segurança precisa melhorar devido à ausência de policiamento em alguns horários e presença de áreas sem infraestrutura (abandonadas), segundo informações dos entrevistados.

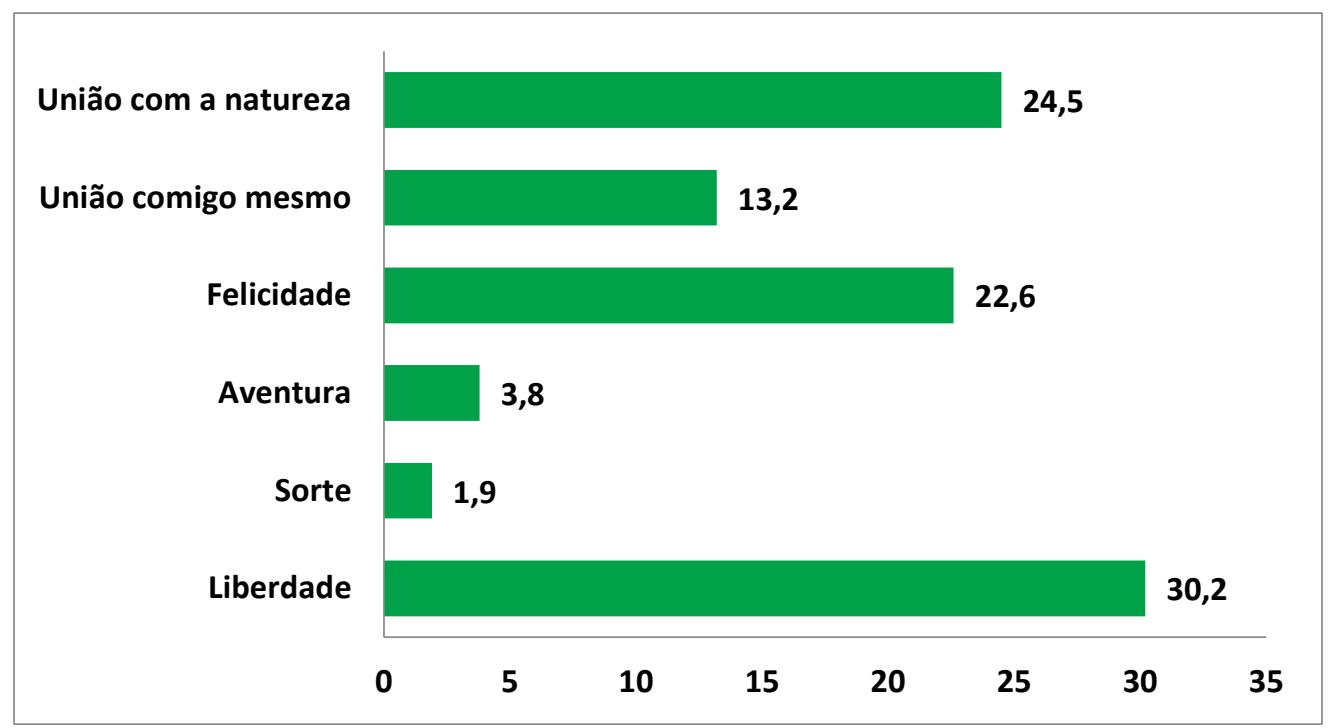

Figura 6a: Sentimentos experimentados ao frequentar o parque.

Figure 6a: Feelings experienced while attending the park.

Fonte: Resultados da pesquisa (2016).

Source: Search results (2016) 
Curiosamente, o sentimento de "medo" é sentido por mais frequentadores do que o sentimento de "conforto" ou "silêncio", podendo existir uma relação com a maioria das respostas informarem que os frequentadores não se sentem seguros nas dependências do parque, conforme demonstrado na Categoria I.

Com relação à maior função do parque (Figura $6 b)$, grande parte $(59,6 \%)$ respondeu "lazer", uma vez que os entrevistados estavam praticando alguma atividade como andar de bicicleta, caminhando, andando de slackline etc. A opção "ecológica" ficou em segundo lugar, seguida por "social" e "outra", permanecendo em último lugar a opção "estética", indicando que na percepção dos visitantes, o Parque do Flamengo possui (ou deveria possuir) um caráter mais ambiental ao invés de estético.

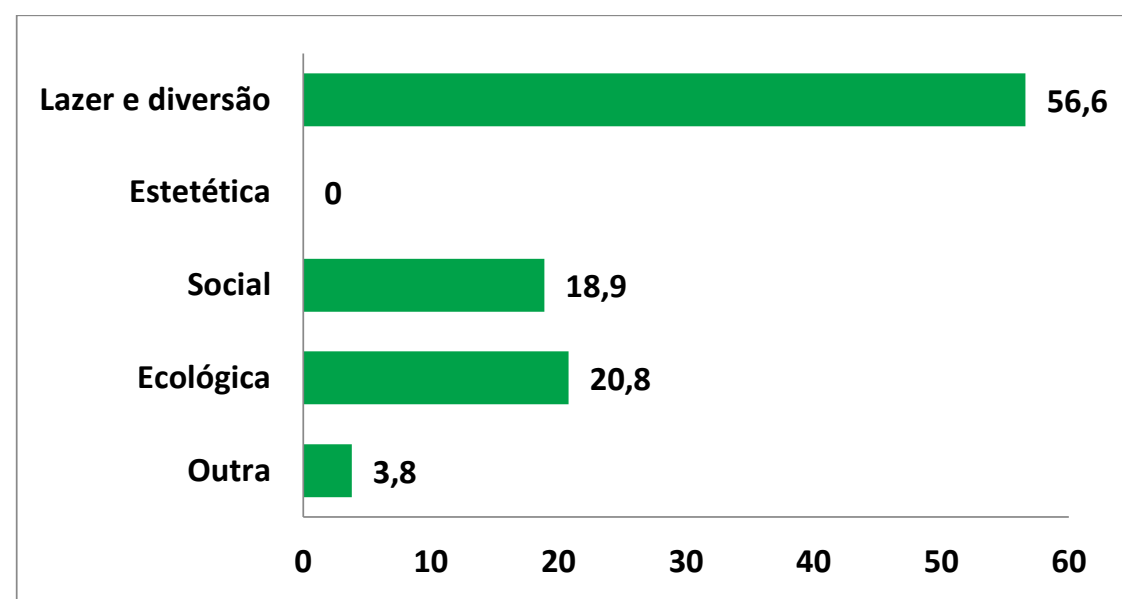

Figura 6b: Função atribuída ao parque pelos frequentadores.

Figure 6b: Role assigned to the park by visitors.

Fonte: Resultados da pesquisa (2016).

Source: Search results (2016).

Quando perguntados sobre a maior atração do parque (Figura 6c), a maior parte $(67,9 \%)$ dos frequentadores elegeu o verde, deixando claro que a população possui noção da importância das áreas verdes urbanas. A segunda maior atração do Parque do Flamengo para os visitantes é a ciclovia, e este fato frente à crise de mobilidade urbana gerada pelo excessivo número de automóveis e péssimas qualidades do transporte coletivo, mostra que a cidade do Rio de Janeiro apresenta características positivas para o uso da bicicleta tornando-se fundamental que ocorram intervenções no sistema cicloviário do município.

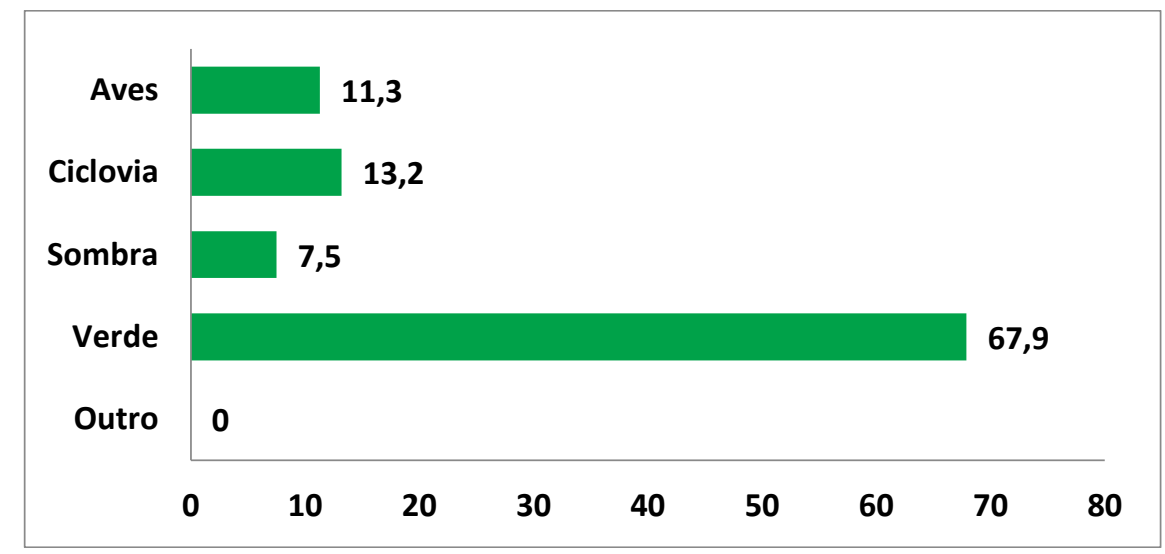

Figura 6c: Atrações oferecidas pelo parque.

Figure 6c: Attractions offered by the park.

Fonte: Resultados da pesquisa (2016).

Source: Search results (2016). 
Além de um sistema cicloviário de qualidade, se deveria promover a integração da bicicleta com os demais meios de transporte, como por exemplo, entre a bicicleta e o ônibus, bicicleta e barcas etc. Os entrevistados também foram questionados quanto aos benefícios trazidos pelo parque (Figura 6d), e a maioria $(43,4 \%$ ) escolheu "saúde" como o principal benefício social oferecido pelo parque, enaltecendo a necessidade da manutenção do parque como uma área da cidade própria para prática de exercícios físicos. Nenhum dos frequentadores indicou como principal benefício do parque a conservação de algum ser vivo, talvez por falta de informação a respeito de áreas como parques urbanos na conservação da fauna e flora.

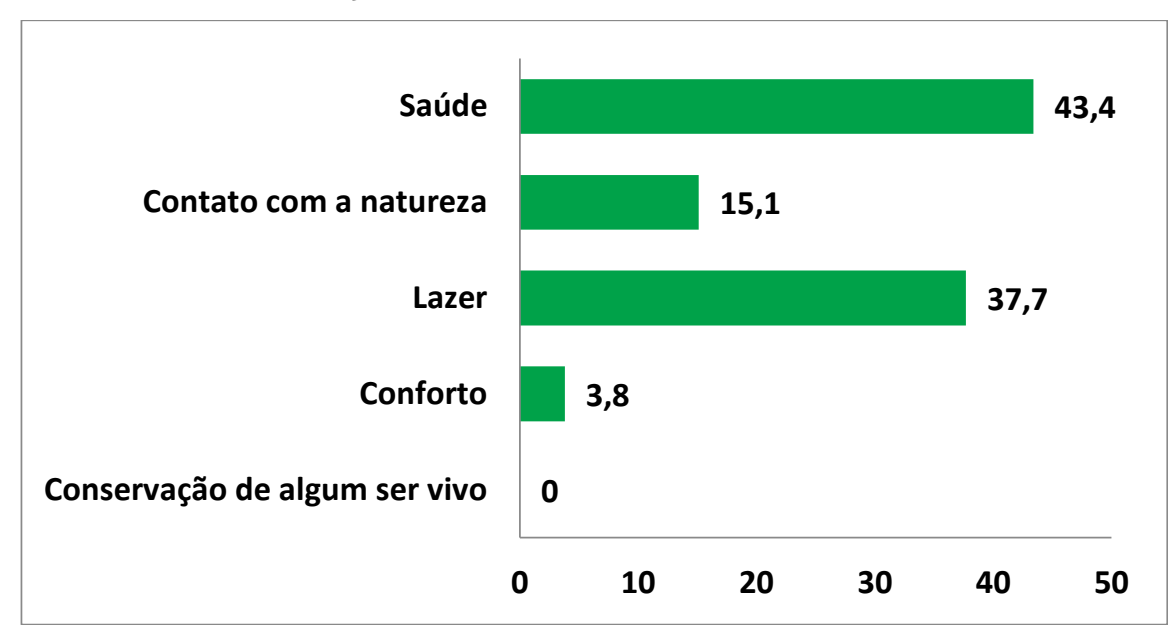

Figura 6d: Tipos de benefícios proporcionados pelo parque.

Figure 6d: Types of benefits provided by the park.

Fonte: Resultados da pesquisa (2016).

Source: Search results (2016).

Sobre a qualidade dos serviços no parque (Figura 6e) a maior parte dos frequentadores $(59,3 \%)$ afirma que estes são apenas razoáveis, pois em alguns trechos, precisam ser melhoradas a ciclovia e a limpeza, além de cobrarem uma segurança mais presente e eficiente.

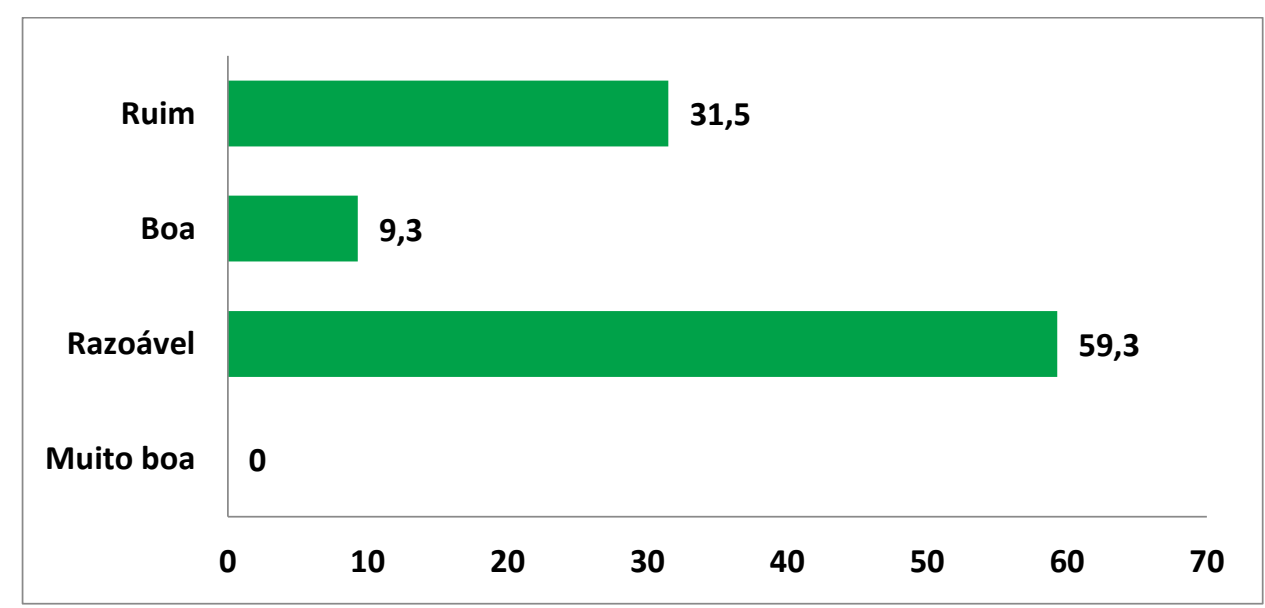

Figura 6e: Percepção qualitativa dos serviços do parque.

Figure 6e: Qualitative perception of park services.

Fonte: Resultados da pesquisa (2016).

Source: Search results (2016). 
A opção mais relevante é o fato de a grande maioria das pessoas que frequentam o parque entenderem que aquele local oferece saúde como maior benefício, porém, a geração de benefícios pelo parque deve ser dispersa de forma recíproca, ou seja, tanto para a sociedade quanto para o meio ambiente.

O que foi evidenciado é que há uma percepção maior sobre o bem-estar que sentimos, mas poucos frequentadores do parque percebem o equilíbrio ambiental conferido ao ecossistema urbano ao redor, pelo parque.

Em relação à biodiversidade residente no parque (figura 6f), a maioria do público (74\%) frequentador diz conhecer ao menos uma espécie animal ou vegetal. Entre os representantes da flora, ipês, abricó de macaco, palmeiras, flamboyants e pau-brasil foram os mais citados; alguns frequentadores optaram por apenas generalizar como "árvores" e algumas pessoas chegaram a citar árvores menos conhecidas como fícus, aroeira, árvore do viajante e até carnaúba, mostrando que é válida a colocação de placas de identificação das plantas, bem como a manutenção corriqueira das mesmas.

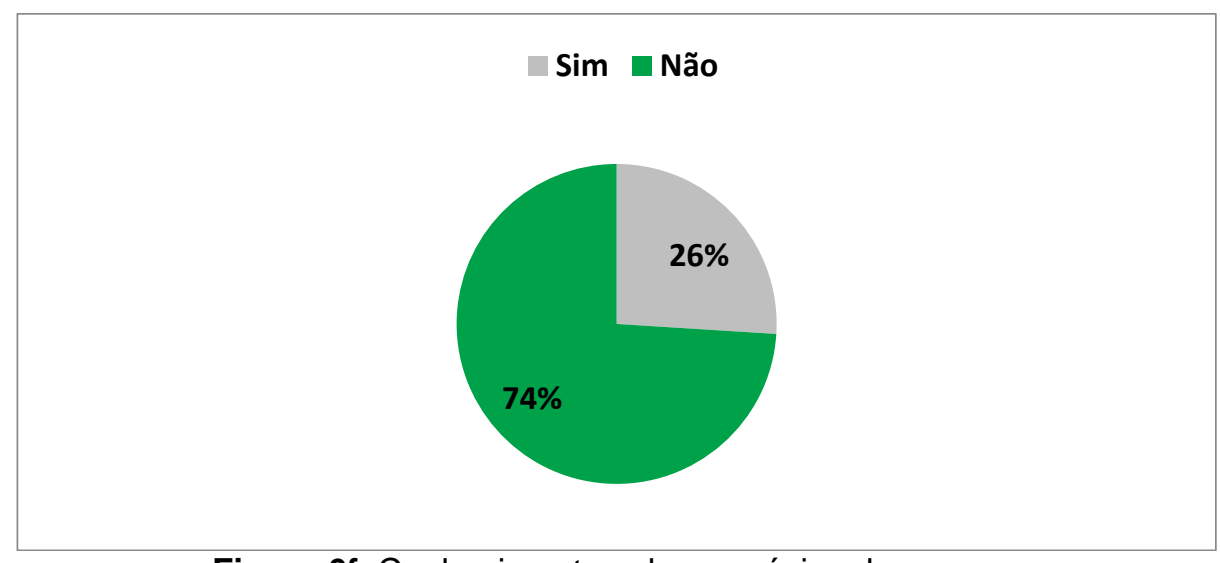

Figura 6f: Conhecimento sobre espécies do parque.

Figure 6f: Knowledge about park species.

Fonte: Resultados da pesquisa (2016).

Source: Search results(2016).

No reino da fauna, psitacídeos foram os mais ditos conhecidos, citados como maritaca, maitaca, papagaios e periquitos. Alguns participantes apenas generalizaram como aves e outros citaram aves marítimas e os gaviões. Curiosamente as tartarugas, que vez ou outra aparecem na praia, também foram citadas por algumas pessoas, demonstrando a amplitude e a importância do parque como meio de disseminar a educação ambiental.

Outros representantes citados e não tão bem-vindos foram os saguis (micos), pombos e gatos domésticos. Alguns frequentadores inclusive desejaram frisar bem a problemática dos gatos domésticos no parque, informando que os mesmos são alimentados por frequentadores, e contribuem por não gerar um ambiente saudável, principalmente em locais que crianças frequentam e brincam.

Há um crescente reconhecimento de áreas urbanas como formas inovadoras para a conservação e promoção da biodiversidade, e os parques, como um tipo específico de espaço verde urbano, constituem importantes hotspots de biodiversidade em meio à paisagem urbana.

Explorar a dimensão emocional das experiências baseadas na natureza, os benefícios que as pessoas percebem, e a relação com o bem-estar pessoal, foi outro importante interesse da pesquisa, categorizado na Categoria III. 
Na verdade, presume-se que as emoções e sentimentos, que nós percebemos no ambiente natural, formam uma parte relevante de nossa experiência no mesmo.

Os candidatos foram convidados a responder as seguintes questões:

•"Qual sensação a natureza desperta em você?". Esta pergunta teve um formato de resposta múltipla. As seguintes opções foram dadas: Liberdade, Sorte, Aventura, Felicidade, União com o meu eu, União com a natureza, e outros, em que o entrevistado podia adicionar outras sensações que não constavam na lista.

•"Quão importante são essas sensações para o seus bem-estar diário?" As respostas foram analisadas em uma escala de medição de 1 -----5 pontos $(1$, nem um pouco importante; 5 , essencial) ; e por quê? Esta foi uma questão em aberto, onde 0 entrevistado poderia motivar sua resposta.

Análise de frequência das respostas obtidas sobre as sensações experimentadas (Figura 7) mostra que "liberdade" é o sentimento mais frequentemente mencionado, correspondendo por $30,2 \%$ das respostas.

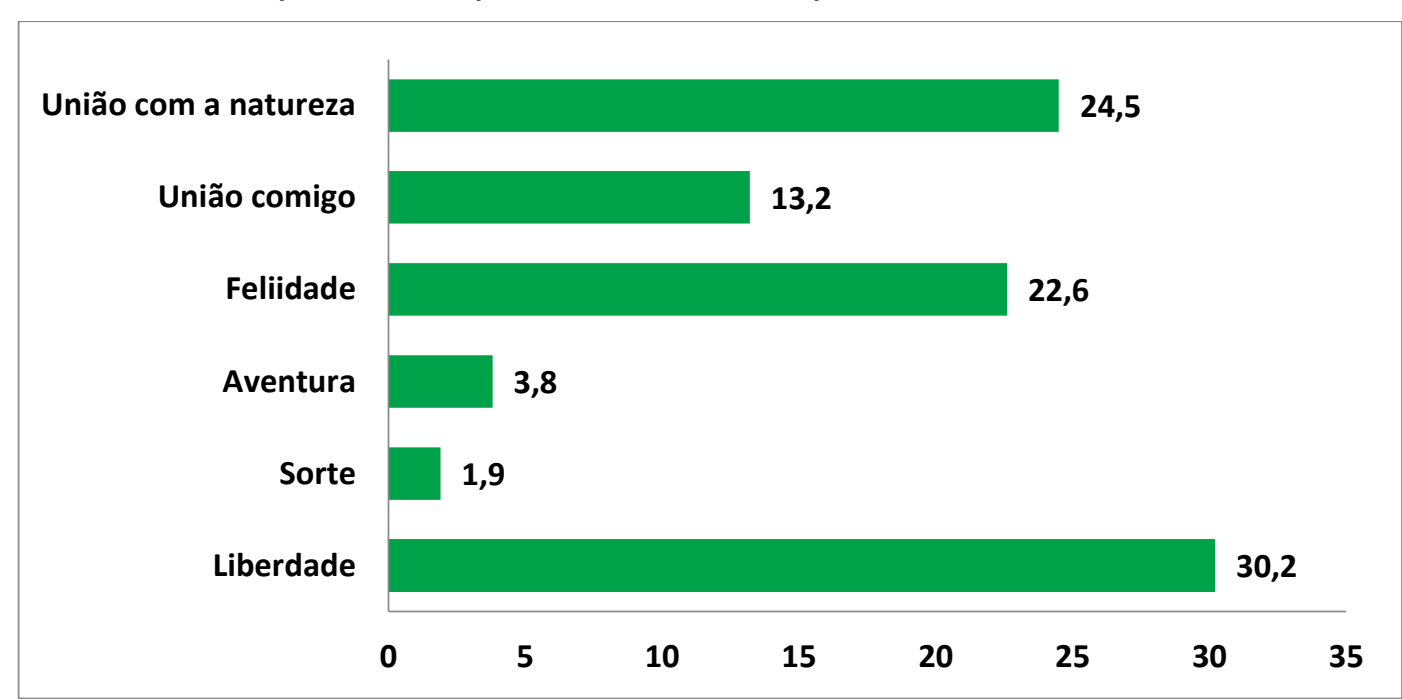

Figura 7: Experiência emocional sentida em meio natural.

Figure 7: Emotional experience felt in the natural environment.

Fonte: Resultados da pesquisa (2016).

Source: Search results (2016).

O sentimento de "união com a natureza" foi escolhido por quase $25 \%$ dos entrevistados. A sensação de estar em união com a natureza implica harmonia com a mesma, e a habilidade para conviver com a realidade extrafísica como pertencendo a ela. A condição de se sentir parte da natureza, formando uma união com ela, implica uma espécie de transcendência do ego e do "self" (MASLOW, 1971).

"Felicidade", "união comigo mesmo" e "aventura" seguem mencionados nesta ordem, e "sorte" é o sentimento menos mencionado que as pessoas experimentam no parque. Outros sentimentos mencionados com frequência foram beleza e tranquilidade. Os itens da pergunta sobre qual sensação a natureza despertava foram divididos como sendo componentes de dois fatores: de "recreação" ou de "espiritualidade" (Tabela 2), sendo "liberdade", "felicidade", "aventura" e "sorte" itens do fator "recreação". 
Tabela 2: Sentimentos na natureza: componentes de fator de recreação e espiritualidade.

Table 2: Feelings in nature: components of recreation factor and spirituality.

\begin{tabular}{|c|c|c|}
\hline \multirow[t]{2}{*}{ Sentimento } & \multicolumn{2}{|c|}{ Componente } \\
\hline & Recreação & Espiritualidade \\
\hline Liberdade & 68 pessoas & \\
\hline Felicidade & 44 pesoas & \\
\hline Aventura & 6 pessoas & \\
\hline Sorte & 4 pessoas & \\
\hline União comigo mesmo & & 28 pessoas \\
\hline União com a natureza & & 50 pessoas \\
\hline Total & & 200 pessoas \\
\hline
\end{tabular}

Fonte: Resultados da pesquisa (2016).

Source: Search results (2016).

A dimensão recreacional é identificada em virtude do fato de que a experiência de conviver com à natureza é fonte de sentimentos positivos, que renovam o espírito. Com o termo "recreação" não se quer referir as atividades particulares que as pessoas realizam durante suas estadias na natureza, mas sim para a sensação de relaxamento e prazer regenerativo que a própria experiência em natureza promove. O segundo fator chamado de "espiritualidade", foi relacionado aos sentimentos "união comigo mesmo" e "união com a natureza". Acredita-se que reflitam a necessidade de alcançar estados mais elevados da mente, para elevar a alma e a mente para além dos pensamentos diários, a sentir-se parte de um todo maior e em harmonia com ela. A atmosfera tranquila do parque inspira reflexão, meditação e uma sensação geral de harmonia entre si mesmo e o entorno.

Os frequentadores do parque também pontuaram a importância desses sentimentos e emoções para o bem-estar diário comum, ao longo de uma escala de medida de 1 - 5 pontos (1, Nem um pouco importante; 2, não importante; 3, importante; 4 , muito importante; 5 , essencial).

A análise mostrou que a maioria (58,2\%) das respostas definiu como essencial o nível de importância desses sentimentos vivenciados em meio à natureza (Figura 8). A descoberta indica que a experiência emocional é percebida como uma contribuição muito importante para o bem-estar das pessoas.

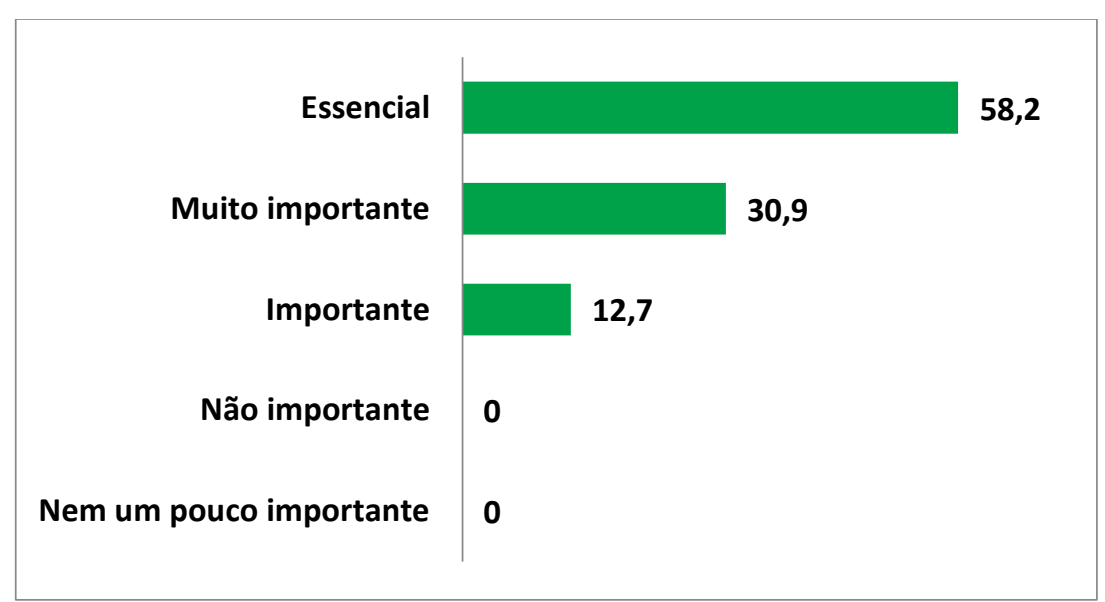

Figura 8: Importância dos sentimentos sentidos em meio à natureza.

Figure 8: Importance of feelings felt in the midst of nature.

Fonte: Resultados da pesquisa (2016).

Source: Search results (2016). 


\section{Respostas abertas}

Explorar as razões pelas quais a experiência na natureza foi percebida ou não como importante pelo bem-estar geral dos entrevistados, foi outro objetivo importante da pesquisa. Os entrevistados puderam articular suas respostas com pensamentos pessoais e valores em uma pergunta aberta.

No questionário, um espaço em branco foi delineado, permitindo expressar pensamentos com palavras próprias. A análise das respostas abertas consistiu em um relato caso a caso das respostas dadas pelos entrevistados, e sobre a sua análise de conteúdo detalhado. Respostas que continham palavras com significados semelhantes eram consideradas como abordando o mesmo motivo subjacente, e assim, agrupadas ao mesmo tema representativo. A Tabela 3 resume os principais temas encontrados $\mathrm{e}$ os argumentos representativos relacionados.

Tabela 3: Questões abertas: dimensões subjacentes.

Table 3: Open questions: underlying dimensions.

\begin{tabular}{l|c}
\hline \multicolumn{1}{c|}{ Motivos } & Dimensão \\
\hline -A natureza relaxa e dá disposição para o dia a dia. & \\
-Posso recarregar as baterias. & \\
- Mantenho o equilíbrio, que me ajuda a focar nos estudos e responsabilidades. & Restaurador \\
-Preciso de contato om o verde para funcionar bem. & \\
\hline -Me dá tranquilidade, que reflete em ações no trato om o próximo. & Deleite \\
- O contato com a natureza me traz paz e calma. & \\
- Alivia o stress diário. & \\
- Sentimento de bem estar. & Espiritual \\
-Estar na natureza faz bem a mente e ao espirito. & \\
- A natureza nos completa e nos dá força pra viver. & \\
- Revitaliza a alma. &
\end{tabular}

Fonte: Resultados da pesquisa (2016). Source: Search results (2016).

O componente "restaurador" reflete a percepção de que estar no ambiente natural compensa o stress da vida diária, e renova o equilíbrio psicofísico das pessoas. Evidências de pesquisas mostram que os ambientes naturais são uma poderosa fonte de experiências de restauração (HARTIG et al., 1987, 1991). Entre os principais componentes da experiência de restauração, Kaplan e Kaplan (1989) mencionam escape, fascínio, extensão, ação e compatibilidade. O componente "deleite" representa a experiência da natureza como desvio da vida quotidiana, como uma ruptura das preocupações e responsabilidades, como uma distração visual dos carros e casas, como lugar para ouvir outros sons que aqueles do tráfego e vozes humanas.

Este componente reflete a necessidade de divagar da rotina diária, se divertir e se envolver em atividades fora das barreiras psíquicas da cidade. Kaplan e Kaplan (1989) descrevem o sentido de "estar fora" como um estado que envolve distanciamento de distrações negativas, ou da rotina do trabalho.

Driver et al. (1991) mencionam o conceito de "fuga temporária", entendida como passivo ou somente mental, tais quais as sentidas por meditação ou admirando pela janela uma vista natural agradável, por exemplo. 
O último componente que surgiu ao analisar o conteúdo das respostas abertas foi chamado de "espiritual". Os argumentos relacionados com este componente (Ver tabela 3) retratam a natureza como fonte primária de energia, a força motriz original, a sustentação e a própria essência da existência humana. A natureza é percebida como uma energia mística que dá sentido para a vida, o que a enriquece e a torna totalmente digna de ser vivida.

Conforme observado por Thompson (2002, p. 65) "para muitas pessoas em cidades, o parque é um lugar onde a natureza pode ter uma dimensão metafísica ou espiritual".

\section{Satisfação com a presença do verde urbano}

A última pergunta, que faz parte da Categoria IV, indagou aos visitantes se "Existem áreas verdes suficientes em sua cidade?".

A maioria (65\%) (Figura 9) das respostas indicou insatisfação com a quantidade de verde urbano atualmente presente na cidade do Rio de Janeiro. Alguns dos questionários que indicaram satisfação com a quantidade de áreas verdes na cidade voltaram acompanhados de observações atentando que falta conservação, cuidado e segurança nas mesmas.

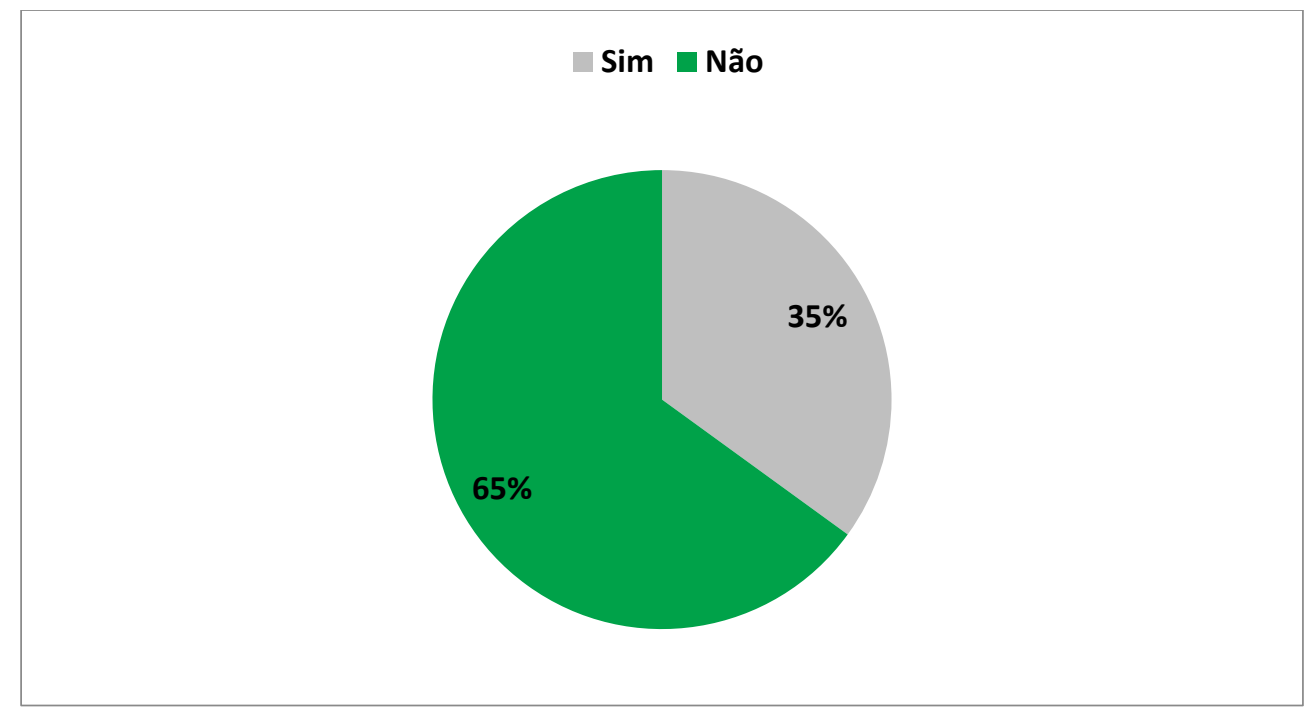

Figura 9: Satisfação pública com o número de áreas verdes.

Figure 9: Public satisfaction with the number of green areas.

Fonte: Resultados da pesquisa (2016).

Source: Search results (2016).

Mc Pherson et al. coletaram dados de 929,823 árvores de 50 cidades do estado da Califórnia. A análise foi desde acúmulo de carbono à retenção de água de chuva, de forma que pudessem encontrar um valor monetário nos serviços ecológicos que o verde da cidade proporciona. Os resultados indicaram que o valor dos serviços prestados aos americanos por 9,1 milhões de árvores da cidade da Califórnia é cerca de US $\$ 1$ bilhão, ou cerca de US \$110,63 por árvore. Em outras palavras, o verde da cidade proporcionar um retorno notável sobre o investimento. As árvores removeram 567.748 toneladas de $\mathrm{CO} 2$ por ano, o equivalente à retirada de 120.000 carros das ruas. Sendo o custo médio anual por gestão de árvores US \$19,00, \$5,82 em benefícios retornam para todos os US \$1 gasto. 
Os valores ressaltam a importância de se plantar árvores, dando importância na diversidade, e prova para os gestores que vale a pena a despesa e os esforços de plantio e manutenção, quando se trata de fazer da cidade um lugar mais bonito e saudável. Ilustra também o quão importante são as organizações e intervenções que visam o plantio e a disseminação do verde para as cidades.

\section{Conclusão}

A informação que surgiu a partir da pesquisa indica que a natureza urbana cumpre parte importante nas necessidades humanas imateriais e de não consumo. Os resultados obtidos vão de acordo com as observações anteriores em relação às pessoas precisarem experimentar a natureza (KAPLAN; KAPLAN, 1989).

As pessoas visitam parques principalmente porque querem relaxar, sendo 0 relaxamento uma necessidade importante cumprida na natureza, juntamente com fascínio, beleza, paz e liberdade (RENEMA et al.,1999). As necessidades para apreciar a natureza e para fugir do estressante ritmo da cidade também constituem razões importantes para as pessoas visitarem o parque. Em um estudo sobre percepção de um parque da cidade, os frequentadores mencionaram, entre outros, o valor de "isolamento do barulho da cidade" (GOBSTER, 2001).

O sentido de "escapar da cidade" também foi encontrado entre os benefícios mais importantes de experiências de vida selvagem (ROSSMAN; ÚLEHLA, 1977).

Resultados indicam que a experiência da natureza na cidade é fonte de uma grande variedade de sentimentos positivos para as pessoas. Entre as mais frequentemente mencionadas estão, União com a natureza, Liberdade e Felicidade, juntamente com a beleza e silêncio. Em Klijn et al. (2000), a liberdade e o silêncio também aparecem como valores centrais no apreço das pessoas pela natureza. Coeterier et al. (1997) verificaram que a sensação de união com a natureza foi evocada especialmente por paisagens contendo o elemento água.

Parques são importantes no bem estar das pessoas, tendo relação com suas experiências emocionais e o bem- estar. Estudos mostram que emoções e sentimentos evocados durante um momento no parque são classificados pelos frequentadores como muito importantes como contribuição para o bem-estar. Benefícios diretos são notados no sentido de regenerar o psicofísico, equilibrar, relaxar, romper com a rotina diária, estimular uma conexão espiritual com o mundo natural. Todos estes benefícios emocionais e psicológicos contribuem de forma considerada para a qualidade de vida, que por sua vez é um componente-chave do desenvolvimento sustentável (PRESCOTT-ALLEN, 1991).

Mesmo possuindo uma natureza imaterial e intangível, os serviços oferecidos pelos parques urbanos são claramente benéficos para o povo, e sua perda poder vir a gerar graves consequências socioeconômicas. A falha em fornecer acesso aos benefícios restauradores e psicológicos da natureza na cidade poderia ter custos substanciais para a saúde em longo prazo (THOMPSON, 2002). Portanto, a avaliação da disponibilidade de serviços psicológicos e sociais em áreas urbanas deve ser integrada ao procedimento de se avaliar projetos e ser devidamente contabilizada nas decisões políticas e de planejamento de estratégias humanas. 
Formas alternativas de avaliação devem ser direcionadas para o debate público, capaz de articular a discussão dos valores estéticos, espirituais e morais e acomodar as necessidades pós-materialistas e orientação de valores (JAMIESON, 1998; BROWN; CAMERON, 2000; CHIESURA. De GROOT, 2003). Valorizar as satisfações e necessidades dos frequentadores é importante para a gestão urbana (BURGESS et al., 1988; MILLWARD; MOSTYN, 1988; COSTA, 1993). Assim, a representação e a participação dos cidadãos, em todos os aspectos da vida urbana são de extrema importância, de forma que uma cidade sustentável precisa ser criada pelas próprias pessoas (CAMAGNI et al., 1998).

Uma cidade sustentável deve satisfazer as necessidades dos seus cidadãos, logo, propõe-se que os indicadores de sustentabilidade para desenvolvimento urbano incluam mais parâmetros voltados às áreas verdes abertas como praças e parques urbanos, bem como índices que demonstrem a percepção e a satisfação dos cidadãos a respeito de seu meio ambiente ao redor.

Os resultados obtidos também evidenciaram adversidade da idade dos frequentadores, então fica sugerido que profissionais da área de arquitetura, paisagismo e designer, levem em conta essa variabilidade, através da gestão de espaços verdes de uma forma diversificada, de modo que satisfaça as necessidades e expectativas de todos os segmentos da população (crianças, famílias, idosos etc.).

O Parque do Flamengo teve sua criação motivada pelo crescimento do meio urbano, recebendo um contexto político, econômico, socioambiental e educativo. Devido ao pequeno tamanho da amostra analisada e as estatísticas limitadas realizadas, conclusões universais não podem ser afirmadas sobre o papel de parques urbanos no geral, no entanto, algumas observações conclusivas podem ser feitas.

A natureza urbana preenche muitas funções sociais e necessidades psicológicas dos cidadãos sendo um recurso valioso municipal e um ingrediente fundamental para a sustentabilidade de uma cidade (ROOVERS et al., 2002), e a avaliação do real valor dos parques para a sociedade deve começar a partir das necessidades, desejos e crenças dos indivíduos que compõem essa mesma sociedade. O envolvimento do público, a participação dos cidadãos e uma avaliação qualitativa de suas necessidades e interesses, devem ajudar comunidades urbanas a articular em valores partilhados em comum que, por sua vez, podem servir como critérios de referência para os planejadores locais vislumbrarem mais estratégias urbanas sustentáveis.

Deve-se fazer com que a sociedade e seus diferentes contextos compreendam o real valor de se preservar as áreas verdes urbanas, principalmente, neste caso, os parques urbanos, que geram benefícios sociais e ambientais tais qual 0 desenvolvimento das atividades humanas, a valorização visual do ambiente e a amenização da temperatura do entorno, estabilização das superfícies pelas raízes das plantas através da permeabilidade e fixação do solo, abrigo à fauna e flora, dentre outros.

Dadas às percepções apresentadas, nota-se que foi possível atingir o objetivo proposto inicialmente e ainda diagnosticar as necessidades do parque para que seus benefícios sociais e ambientais possam ser potencializados ainda na geração presente. 


\section{Referências}

BEDIMO-RUNG, A.L.; MOWEN, A.J.; COHEN, D.A. The significance of parks to physical activity and public health: A conceptual model. American Journal of Preventive Medicine, v. 28, p. 159-168, 2005.

BISHOP, I.D.; YE, W.S.; KARADAGLIS, C. Experiential approach to perception response in virtual worlds. Landscape and Urban Planning, v. 54, p. 115- 123, 2001.

BROWN, P.M.; CAMERON, L.D. What can we do to reduce over- consumption. Ecological Economics. v. 1(32), p. 27-42, 2000.

BRUN, E.J.; BRUN, F.G.K. Arborização Urbana \& Qualidade de vida. Conselho em Revista. Porto Alegre, RS. Ano 3, n. 18, p. 27, 2006.

BURGESS, J.; HARRINSON, C.M.; LIMB, M.; People, parks and the urban green: a study of popular meanings and values for open spaces in the city. Urban Studies. v. 25, p. 455-473, 1998.

CAMAGNI, R.; R. CAPELLO; P. NIJKAMP. "Towards Sustainable City Policy: An Economy-Environrnent Technology Nexus". Ecological Economics, v. 24, p. 103-108, 1998.

CHIESURA, A.; De GROOT, R. S. Critical natural capital: a socio-cultural perspective. Ecological Economics. v. 44, p. 219-231, 2003.

COETERIER et al. Perception of the Wadden sea Area. Investigating the Values of Visitors and Inhabitants. Wageningen, DLO - StaringCentrum, 1997.

CORNELL, E.H.; HADLEY, D.C., STERLING, T.M., et al., 2001. Adventure as stimulus for cognitive development. Journal of Environmental Psychology, v. 21, n. 3, p. 219231, 2001.

CUSTANCE, D.M.; MAYER, J. Empathic-like responding by domestic dogs (Canis familiaris) to distress in humans: An exploratory study. Animal Cognition, 15(5), p. 851859, 2012.

DRIVER, B.L.; BROWN, P.J.; PETERSON, G.L. Benefits of Leisure. Venture Publishing, State College, PA, US, p. 483, 1991.

FERNANDES, E. Impacto socioambiental em áreas urbanas sob a perspectiva jurídica. In: MENDONÇA, F. (org). Impactos Socioambientais Urbanos. Curitiba: Ed. UFPR, p. 99-128, 2004.

GOBSTER, P.H. Visions of nature: conflict and compatibility in urban park restoration. Landscape and Urban Planning, v. 56, p.35-51, 2001.

HARTIG, T.; MANG, M.; EVANS, G.W. Perspectives on Wilderness: testing the theory of restorative environments. In: EASLEY, P. (Eds.), The Use of Wilderness for Personal Growth, Therapy, and Education. Estes Park, CO, 1987.

HARTIG, T.; MANG, M.; EVANS, G.W. Restorative effects of natural environment experience. Environment and Behavior, v. 23, p. 3-26, 1991.

HENKE-OLIVERIA, C. Planejamento ambiental na cidade de São Carlos (SP) com ênfase nas áreas públicas e áreas verdes: diagnóstico e propostas. Dissertação (Mestrado) - Universidade Federal de São Carlos, São Paulo, p. 11, 1996. 
JAMIESON, D. Sustainability and beyond. Ecological Economics. v. 2-3 (24), p. 183$192,1998$.

JAPYASSÚ, H. F.; BRESCOVIT, A. Biodiversidade araneológica na cidade de São Paulo: a urbanização afeta a riqueza de espécies? $3 p$. Disponível em: $<$ www.ambientebrasil.com.br>. Acesso em: 21/01/2016.

KLIJN, J.A.; BUIJ, A.E.; DIJKSTRA, H.; LUTTIK, J.; VEENEKLAAS, F.R. The Forgotten Values of Nature and Landscape. Use and Appreciation Measured in Money and Emotional Value. Alterra Green World Research, Wageningen, 2000.

KAPLAN, S.; KAPLAN, R. The Experience of Nature. A Psychological Perspective. Cambridge University Press, Cambridge, p. 340, 1989.

LIBRETT, J.; HENDERSON, K.; GODBEY, G.; MORROW JR, J. R. An introduction to parks, recreation, and public health: Collaborative frameworks for promoting physical activity. Journal of Physical Activity \& Health, 4, S1-S13, 2007.

LOBODA, C.A.; ANGELIS, B.L.D. Áreas verdes públicas urbanas: conceitos, usos e funções. Ambiência, Guarapuava, v. 1, n. 1, p. 125-139, 2005.

LOMBARDO, M.A. Vegetação e clima. In: III Encontro sobre arborização urbana, Curitiba. Anais... Curitiba, 1990. p. 01 -13, 1990.

MACEDO, S.S.; SAKATA, F.G. Parques Urbanos no Brasil. Brazilian Urban Parks. São Paulo: Universidade de São Paulo (EdUSP), 2003.

MALHEIROS, M.R.T.L. O processo de pesquisa na graduação. Disponível em: $<$ www.profwillian.com/ diversos/download/prof/marciarita/

Pesquisa na Graduacao.pdf>. Acesso em: 17/04/2016.

MASLOW, A.H. The Farther Reaches of Human Nature. New York, NY: The Viking Press, 1971.

MATIAS, L.F; CAPORUSSO, D. Áreas Verdes Urbanas: Avaliação Conceitual e Metodológica a partir do Estudo de caso na cidade de Paulínia - São Paulo, Brasil. Campinas: UNICAMP. 2009.

McPHERSON, G.E.; DOORN, N.; GOEDE, J. Structure, function and value of street trees in California, USA. Urban Forestry \& Urban Greening, EUA, v. 17, abril. 2016. Disponível em: <www.fs.fed.us//> Acesso em: 22/06/2016.

MENDONÇA, F.A. Geografia, planejamento urbano e ambiente. In: SOUZA, A. J. SOUZA, E.B.C.; JÚNIOR, L.M. Paisagem, Território e Região. Em busca da identidade. Cascavel: EDUNIOESTE, p.39-47, 2000.

MILLWARD, A.; MOSTYN, B. People and Nature in Cities: The Social Aspects of Planning and Managing Natural Parks in Urban Areas. Urban Wildlife Now, Nature Conservancy Council, Peterborough,UK, 1998.

PACHECO, E.; SILVA, H.P. Compromissos epistemológicos do conceito de percepção ambiental. 2007. Disponível em: <www.ivt-ri.net/sapis/ 2006/pdf/EserPacheco.pdf> Acesso em: 17/06/2016.

PREFEITURA DA CIDADE DO RIO DE JANEIRO (PCRJ). 1998. Guia das Unidades de Conservação Ambiental do Rio de Janeiro. Rio de Janeiro: IBAM/ DUMA, PCRJ/ SMAC. PRESCOTT - ALLEN, R. Caring for the Earth: A Strategy for Sustainable Living. IUCN - The World Conservation Union, United Nation Environmental Program, Worldwide Fund for Nature, Gland, Switzerland, p. 208, 1991. 
REIGOTA, M. Meio ambiente e representação social. 5.ed. São Paulo: Cortez, 2002. RENEMA, D.; VISSER, M.; EDELMANN, E.; MORS, B. Dewensen van Nederlanders ten aanzien van natuur en groen in de leefom geving (The Wants of the Dutch for Nature and Green in the Living Environment) (in Dutch). Wageningen, DLO-Staring Centrum, 1999.

ROOVERS P.; HERMY M.; GULINCK H. Visitor profile, perceptions and expectations in forests from a gradient of increasing urbanisation in central Belgium. Ladscape and Urban Planning, v. 59. p. 129-145, 2002.

ROSSMAN, B.B., ULEHLA, Z.J. Psychological reward values associated with wilderness use. Environmental and Behavior, v. 9, n.1, p. 41-65, 1977.

SANTUCCI, J. As Promenades do Rio de Janeiro: O Papel do Passeio Público, Praça Paris e Parque do Flamengo na história da paisagem carioca. Rio de Janeiro: UFRJ/FAU. Dissertação de Mestrado em Arquitetura.2003.

TERRA, C.G. (Coord.). Arborização: ensaios historiográficos do Rio de Janeiro: EBA/UFRJ, 2004.

THOMSON, N. Listas de aves registradas no Aterro do Flamengo - Alfredo Heleno. Disponível em: <www.taxeus.com.br/lista/2977>. Acesso em: 25/04/2016.

THOMPSON, C.W. Urban open space in the 21 st century. Landscape and Urban Planning, v. 60, p. 59-72, 2002.

TOLEDO, E.S.; Santos, D.G. Espaços livres de construção. Revista da Sociedade Brasileira de Arborização Urbana, Piracicaba-SP, v. 3, n. 1, p. 73-91, 2008.

VIEIRA, P. B. H. Uma visão geográfica das áreas verdes de Florianópolis, SC: estudo de caso do Parque Ecológico do Córrego Grande (PECG). Florianópolis: Universidade Federal de Santa Catarina, 2004.

Phillipe Knippel do Carmo Graça: Universidade Federal Rural de Pernambuco, PE, Brasil

E-mail: lipekgraca@gmail.com

Link para o currículo Lattes: http://lattes.cnpq.br/7054060300294820

Flávio Pereira Telles: Universidade Federal Fluminense, RJ, Brasil

E-mail: flaviotelles@gmail.com

Link para o currículo Lattes: http://lattes.cnpq.br/3725769597958042

Data de submissão: 13 de outubro de 2019

Data de recebimento de correções: 21 de agosto de 2020

Data do aceite: 21 de agosto de 2020

Avaliado anonimamente 